\title{
Brain Potentials Reflect Behavioral Differences in True and False Recognition
}

\section{Citation}

Curran, Tim, Daniel L. Schacter, Marcia K. Johnson, and Ruth Spinks. 2001. Brain potentials reflect behavioral differences in true and false recognition. Journal of Cognitive Neuroscience 13(2): 201-216.

\section{Published Version}

doi:10.1162/089892901564261

\section{Permanent link}

http://nrs.harvard.edu/urn-3:HUL.InstRepos:3627266

\section{Terms of Use}

This article was downloaded from Harvard University's DASH repository, and is made available under the terms and conditions applicable to Other Posted Material, as set forth at http:// nrs.harvard.edu/urn-3:HUL.InstRepos:dash.current.terms-of-use\#LAA

\section{Share Your Story}

The Harvard community has made this article openly available.

Please share how this access benefits you. Submit a story.

Accessibility 


\title{
Brain Potentials Reflect Behavioral Differences in True and False Recognition
}

\author{
Tim Curran ${ }^{1}$, Daniel L. Schacter ${ }^{2}$, Marcia K. Johnson ${ }^{3}$, and \\ Ruth Spinks ${ }^{1}$
}

\begin{abstract}
People often falsely recognize nonstudied lures that are semantically similar to previously studied words. Behavioral research suggests that such false recognition is based on high semantic overlap between studied items and lures that yield a feeling of familiarity, whereas true recognition is more often associated with the recollection of details. Despite this behavioral evidence for differences between true and false recognition, research measuring brain activity (PET, fMRI, ERP) has not clearly differentiated corresponding differences in brain activity. A median split was used to separate subjects into Good and Poor performers based on their discrimination of studied targets from similar lures. Only Good performers
\end{abstract}

\section{INTRODUCTION}

Understanding of human memory has been advanced by the investigation of memory errors, distortions, and illusions (Schacter, Norman, \& Koutstaal, 1998; Roediger, 1996; Johnson, Hashtroudi, \& Lindsay, 1993). Such research indicates that memory is often a reconstructive process rather than a verbatim record of past events, and that remembering entails attributions about the origin of the information that comes to mind. Theoretical discussions of these attributional or "source monitoring" processes emphasize that true and false memories arise via powerful but imperfect cognitive processes. For example, memory distortions sometimes occur because people lack or do not access ("recollect") critical event details, or because people inappropriately weigh one kind of information (e.g., familiarity) out of proportion to its diagnostic value (e.g., Schacter, Israel, \& Racine, 1999; Johnson et al., 1993; Johnson \& Raye, 1998; Curran, Schacter, Norman, \& Galluccio, 1997). Recent event-related brain potential (ERP) and neuroimaging studies suggest that true and false memories sometimes can be distinguished in brain activity (Johnson et al., 1997; Schacter, Reiman, et al., 1996), as we would expect based on the assumption that they come from feature distributions that do not completely over-

\footnotetext{
${ }^{1}$ Case Western Reserve University, ${ }^{2}$ Harvard University, ${ }^{3}$ Yale University
}

showed late (1000-1500 msec), right frontal event-related brain potentials (ERPs) that were more positive for targets and lures compared with new items. The right frontal differences are interpreted as reflecting postretrieval evaluation processes that were more likely to be engaged by Good than Poor performers. Both Good and Poor performers showed a parietal ERP old/new effect (400-800 msec), but only Poor performers showed a parietal old/lure difference. These results are consistent with the view that the parietal and frontal ERP old/new effects reflect dissociable processes related to recollection.

lap (e.g., Johnson \& Raye, 1981). Here, we compare the brain activity of individuals who show Good versus Poor discrimination between old items and semantically related new items in order to help identify the brain processes underlying the cognitive processes involved in remembering.

Many recent studies of false memory have used a procedure reported initially by Deese (1959) and subsequently modified by Roediger and McDermott (1995) in which subjects falsely remember words that are semantically associated to previously studied words (the "DRM procedure"). Roediger and McDermott's subjects heard lists of semantically associated words (e.g., candy, sour, sugar, bitter, good, taste, tooth, etc.) that were related to a nonpresented theme word (e.g., sweet). When the theme words were presented as lures on a recognition memory test, subjects claimed to recognize the critical lures as often as actually heard words. These results are generally consistent with models of memory in which recognition judgments are based on the global similarity between studied and tested items (e.g., Arndt \& Hirshman, 1998; Shiffrin \& Steyvers, 1997; Clark \& Gronlund, 1996; Humphreys, Bain, \& Pike, 1989; Hintzman, 1988; Gillund \& Shiffrin, 1984; Murdock, 1982). Computation of global similarity is often thought to underlie the "familiarity" component of dual-processes theories of recognition memory, whereas "recollection" entails the retrieval of information about individual items (Brainerd, Reyna, \& Kneer, 1995; Hintzman \& Curran, 1994; Yone- 
linas, 1994; Jacoby, 1991). Similarly, in the source-monitoring framework, familiarity is proposed to arise from a less differentiated phenomenal experience than does the experience of recollection (Johnson et al., 1993).

Several studies have sought to differentiate the phenomenal characteristics of true and false recognition with the DRM paradigm. The "remember-know" procedure requires subjects to differentiate between items "remembered" through detailed recollection and items merely "known" as previously studied based on vague feelings of familiarity (Gardiner \& Java, 1993; Tulving, 1985). False alarms to critical lures are sometimes associated with a high rate of "remember" responses (Mather, Henkel, \& Johnson, 1997; Norman \& Schacter, 1997; Roediger \& McDermott, 1995), suggesting that subjects are falsely recollecting illusory perceptual details about nonstudied words. However, such responses also may reflect high-confidence judgments based on semantic familiarity (Curran et al., 1997; Hirshman \& Master, 1997; Donaldson, 1996). In fact, carefully probing the characteristics of "remembering" has revealed that recollection of perceptual details (e.g., auditory attributes of the studied words) is more prevalent in true than false recognition (Mather et al., 1997; Norman \& Schacter, 1997). Such average differences between true and false memories are consistent with the proposal that true and false memories arise from common processes applied to memories that differ in qualitative characteristics depending on their source (Johnson et al., 1993; Johnson \& Raye, 1981).

A related line of research with the DRM paradigm has asked whether true and false recognition are associated with different patterns of brain activity as we would expect based on behavioral evidence such as subjective ratings. A PET study suggested that temporo-parietal brain regions involved with auditory/phonological processing are more active during true recognition of previously heard words than false recognition of semantically similar lures (Schacter, Reiman, et al., 1996). This pattern of activation is consistent with greater retrieval of perceptual detail for true than false memories, but no evidence of temporoparietal activation during true or false recognition was observed with fMRI when test conditions were either blocked (as in PET) or mixed (Schacter, Buckner, Koutstaal, Dale, \& Rosen, 1997). Overall, small PET and fMRI differences between true and false recognition have been dwarfed by similarities in memory-related brain areas such as the medial temporal lobe (parahippocampal cortex and hippocampus). ERPs have also revealed more similarities than differences between true and false recognition (Düzel, Yonelinas, Mangun, Heinze, \& Tulving, 1997; Johnson et al., 1997).

ERPs can be sensitive to the recollection of details. Curran (2000) used study lists with singular and plural words (e.g., tables, book). Subsequent recognition tests included studied words (tables), plurality-reversed lures (books), and new items (following, Hintzman, Curran, \&
Oppy, 1992; Hintzman \& Curran, 1994, 1995). ERPs were measured during a recognition test in which subjects were told to respond "yes" only if the test word was studied in the same plurality. A left, superior, anterior N400-like component (300-500 msec) was more negative for new words than lures or studied words, so it behaved consistently with a familiarity process that was insensitive to the plurality of studied words. This familiarity-sensitive component was dubbed the "FN400" because it was similar to the N400 (e.g., Kutas \& Hillyard, 1980; Kutas \& Van Petten, 1994), but more frontally distributed (see also, Curran, 1999). Left parietal ERPs (400-800 msec) were more positive for studied words than for lures or new words-suggesting a specific recollection process that was sensitive to the plurality of studied words. Rugg and colleagues have identified a similar, "left parietal ERP old/new effect" that they suggest is related to the recollection of specific information (reviewed in, Allan, Wilding, \& Rugg, 1998). The parietal old/new effect has been associated with source recollection (Wilding, Doyle, \& Rugg, 1995; Wilding \& Rugg, 1996, 1997a, 1997b), recollection of associative information (Donaldson \& Rugg, 1998, 1999; Tendolkar, Doyle, \& Rugg, 1997; Rugg, Schloerscheidt, Doyle, Cox, \& Patching, 1996), and discrimination between studied words (e.g., BARTER, VALLEY) and nonstudied conjunctions (e.g., BARLEY) (Rubin, Van Petten, Glisky, \& Newberg, 1999). Furthermore, the parietal old/new effect is larger when subjects judge recognized items as "remembered" than "known" (Rugg, Schloerscheidt, \& Mark, 1998; Düzel et al., 1997; Smith, 1993).

Frontal ERP effects have been related to source recognition in a number of studies. Late frontal ERPs have been associated with recognition of study-source attributes such as format (words vs. pictures; Johnson, Kounios, \& Nolde, 1996), speaker's voice (Wilding \& Rugg, 1996, 1997a; Wilding, 1999; Senkfor \& Van Petten, 1998), encoding task (Wilding, 1999), associative pairing (Donaldson \& Rugg, 1998), and temporal order (Trott, Friedman, Ritter, Fabiani, \& Snodgrass, 1999). These effects are often greater over the right hemisphere where late ERPs (600-1900 msec) are more positive in response to old than new stimuli (reviewed in Allan et al., 1998). Contradictory reports have indicated that the late frontal positivity is greater for old stimuli associated with correct than incorrect source judgements (Wilding \& Rugg, 1996; Wilding, 1999), equivalent for correct and incorrect source judgments (Senkfor \& Van Petten, 1998), and greater for incorrect than correct source judgments (Trott et al., 1999). Previous investigators have often related late, frontal ERP recognition effects to postretrieval strategic evaluation processes (Wilding \& Rugg, 1997a, 1997b; Wilding, 1999; Allan et al., 1998; Johnson et al., 1996).

Previous ERP studies have investigated the DRM paradigm, but results have been mixed. Johnson et al. (1997) observed that late (775-1500 msec), broadly distributed 
(including parietal and frontal regions) voltages differed between true and false recognition only when test items were blocked by condition, but not when items were randomly intermixed like most behavioral experiments. Johnson et al. reasoned that subjects may rely primarily on familiarity when old words and lures are randomly intermixed, but rely more heavily on recollecting specific details under blocked conditions. Düzel et al. (1997) measured ERP during DRM tests that included remember-know judgments and mixed-condition test blocks. ERP differences between words given affirmative recognition judgments and new words included a frontocentral N400-like component associated with "knowing" (300-600 msec), a parietal effect associated with "remembering" (600-1000), and a right frontal effect associated with both remembering and knowing. However, these effects were similar for true and false recognition. In contrast, Johnson et al. observed frontal and parietal differences between studied words and lures when study lists were blocked. Johnson et al.'s frontal/parietal ERP differences were not clearly differentiated and encompassed a large time window (775-1500 msec) that could include both the parietal and late frontal ERP old/new effects previously reported in the literature.

Linking ERP differences between true and false recognition specifically to either the parietal or right frontal ERP effects could help to clarify the relation between cognitive processes (e.g., retrieving details and evaluating information) and underlying brain mechanisms. Although the neural sources of scalp-recorded ERPs cannot be readily localized, some evidence is consistent with the idea that the parietal ERP old/new effect arises from medial temporal lobe activity (Düzel et al., 1999) or cortico-hippocampal interactions (Rugg, Walla, et al., 1998; Wilding \& Rugg, 1996). Such cortico-hippocampal interactions may underlie the revival of specific featural information that is characteristic of recollection (O'Reilly, Norman, \& McClelland, 1998; McClelland, McNaughton, \& O'Reilly, 1995). Amnesic patients with diencephalic and/or medial temporal lobe pathology have shown reduced levels of both true and false recognition in the DRM paradigm (Schacter, Verfaellie, \& Pradere, 1996; Schacter, Verfaellie, \& Anes, 1997; Schacter, Verfaellie, Anes, \& Racine, 1998) and related paradigms using perceptually similar lures (Koutstaal, Schacter, Verfaellie, Brenner, \& Jackson, 1999; Schacter, Verfaellie, et al., 1997). Furthermore, the parietal ERP old/new effect has been found to be greater for correct recognition than false recognition of similar lures (Curran, 2000; Rubin et al., 1999; Schacter, Buckner, et al., 1997; Donaldson, 1996; but see Schacter, Reiman, et al., 1996).

There are also reasons to believe that the right frontal ERP old/new effect may be important for discriminating true and false recognition. Right frontal lesions can increase false recognition rates, even when lures are not extremely similar to studied targets (Curran et al., 1997; Schacter, Curran, Galluccio, Milberg, \& Bates,
1996). A PET study using the DRM paradigm identified bilateral prefrontal activity related to both true and false recognition (Schacter, Reiman, et al., 1996). Event-related fMRI revealed that this prefrontal activity had a later onset than other memory-related activations (e.g., medial temporal lobe, Schacter, Buckner, et al., 1997). The late onset suggests a similarity with late time-course of ERP frontal old/new effects, and is consistent with the activity of a postretrieval evaluation process.

In summary, there are theoretical reasons to believe that either parietal or right frontal ERPs might be different for true and false recognition, but the available evidence is mixed. The present ERP study of the DRM paradigm has two primary advantages over past studies. First, the present experiment measured ERPs with a high-density (128 channel) recording apparatus to more clearly differentiate the parietal and frontal ERP old/new effects. Second, the present experiment attempted to more directly relate the ERP effects to recognition performance by capitalizing on individual differences in discrimination between old words and lures. Several studies using the DRM procedure have shown that older adults discriminate between previously studied words and related lures less well than do younger subjects (Balota et al., 1999; Kensinger \& Schacter, 1999; Schacter et al., 1999; Tun, Wingfield, Rosen, \& Blanchard, 1998; Norman \& Schacter, 1997). There also are indications that between-subject differences exist within the young population. Previous research has shown that correct recognition of targets is positively correlated with subjects' ratings of retrieval of various contextual details (auditory information, affective reactions, associations), whereas false recognition of lures is positively correlated only with rated retrieval of associations to the test item (e.g., other items on the list; Mather et al., 1997). Thus, subjects meaningfully vary in their responses to old words and lures, and this variation is related to the information upon which their responses are based.

A large number of subjects $(n=46)$ participated in the present DRM experiment with ERPs measured during the test. Subjects were divided into groups of "Good" and "Poor" performers based on their ability to discriminate between old words and lures. It was expected that ERP differences between old words and lures would be larger for Good than Poor performers. These differences could correspond to either the parietal or late frontal ERP old/new effects related to source recollection in previous research.

\section{RESULTS}

\section{Behavioral Results}

Behavioral results (summarized in Table 1) were analyzed with two-tailed $t$ tests. The proportion of "yes" responses, $p$ (yes), was higher for old words than lures, 
Table 1. Proportion of "Yes" Responses, Accuracy $\left(A^{\prime}\right)$, and Response Bias $\left(\mathrm{B}^{\prime \prime} \mathrm{D}\right)$

\begin{tabular}{|c|c|c|c|c|c|c|c|}
\hline \multicolumn{8}{|c|}{ Group $^{a}$} \\
\hline & & All Ss & Good & Poor & $t$ & $S E$ & $p$ \\
\hline \multirow[t]{3}{*}{$p$ ("yes") } & Old & 0.63 & 0.70 & 0.56 & 3.08 & .05 & $<.001 *$ \\
\hline & Lure & 0.53 & 0.49 & 0.57 & 2.04 & .04 & $<.05^{*}$ \\
\hline & New & 0.23 & 0.20 & 0.26 & 1.38 & .04 & $>.10$ \\
\hline \multirow[t]{2}{*}{$A^{\prime}$} & Old/lure & 0.58 & 0.67 & 0.49 & 9.1 & .02 & $<.001 *$ \\
\hline & Lure/new & 0.74 & 0.74 & 0.75 & 0.22 & .02 & $>.10$ \\
\hline \multirow[t]{2}{*}{$\mathrm{B}^{\prime \prime} \mathrm{D}$} & Old/lure & -0.29 & -0.36 & -0.21 & 1.2 & .12 & $>.10$ \\
\hline & Lure/new & 0.46 & 0.57 & 0.35 & 1.83 & .12 & .07 \\
\hline
\end{tabular}

$t$ tests compare Good and Poor performers (two-tailed, $d f=44$ ).

${ }^{a}$ Subjects above (Good) and below (Poor) the median in discrimination of old items and lures.

${ }^{*} p<.05$.

$t(45)=4.52, S E=.02, p<.001$; and higher for lures that new words, $t(45)=15.38, S E=.02, p<.001$.

$A^{\prime}$ is a measure of discrimination accuracy ranging from 0 to 1 ( 0.5 is chance, 1.0 is perfect). In a typical recognition memory experiment, $A^{\prime}$ is used to measure discrimination between $p$ (yes) for old items (hit rate) and new items (false alarm rate) (Donaldson, 1992). In the present experiment, we are primarily interested in discrimination between old words and lures, so $A^{\prime}$ (old/ lure) was computed from the $p$ (yes) values of these conditions. $A^{\prime}$ (old/lure) provides an estimate of subjects' ability to discriminate between old words and lures. Subsequent ERP analyses compared subjects who were Good versus Poor at this discrimination by performing a median split on $A^{\prime}$ (old/lure). Table 1 shows the results of $t$ tests comparing subjects above the median ("Good," $n=23$ ) to those subjects below the median ("Poor," $n=23$ ). As expected from the subject selection procedures, Good performers had a higher hit rate to old words and a lower false alarm rate to lures than Poor performers. The groups did not differ in discrimination between lures and new items, $A^{\prime}$ (lure/new).

$\mathrm{B}^{\prime \prime} \mathrm{D}$ is a measure of response bias with negative values indicating a liberal response bias and positive values indicating a conservative response bias. The Good group showed a marginally significant tendency to respond more conservatively (i.e., bias toward "no" responses) than the Poor group when responses to lures and new items were compared. Response time (RT) was analyzed, but RTs are influenced by the requirement to withhold response until after test-word offset (1995 msec after onset). The delayed response procedure may artifactually eliminate RT differences between conditions, but any observed differences can be meaningfully interpreted. A Group $\times$ Condition (old, lure, new) $\times$ Re- sponse (no, yes) ANOVA culminated in a three-way interaction, $F(2,88)=3.78, M S E=26705, p<.05$. The corresponding pattern (see Figure 1) indicates that Poor performers showed similar RTs in all conditions. Good performers were faster within each condition on correct responses (old[yes], lure[no], new[no]) than incorrect responses (old[no], lure[yes], new[yes]). Good performers were especially slow for false alarms ("yes" to lure or new). Overall, it appears that the Good performers were responding more carefully than the Poor performers.

\section{ERP Results}

ERPs were computed for three different conditions: old items given "yes" responses (old[yes]), lures given "yes" responses (lure[yes]), and new items given "no" responses (new[no]). ERPs were baseline-corrected with respect to the 495-msec prestimulus recording interval and digitally low-pass filtered at $40 \mathrm{~Hz}$. An averagereference transformation was used to minimize the effects of reference-site activity and accurately estimate the scalp topography of the measured electrical fields (Dien, 1998; Picton, Lins, \& Scherg, 1995; Tucker, Liotti, Potts, Russell, \& Posner, 1994; Curran, Tucker, Kutas, \& Posner, 1993; Bertrand, Perin, \& Pernier, 1985; Lehman \& Skrandies, 1985).

The measured head space was divided into eight spatial regions to analyze the spatial scalp topography of the ERP effects (see Figure 2, following Curran, 2000): 2 Lateral (left, right) $\times 2$ Caudal (anterior, posterior) $\times 2$ Vertical (inferior, superior). These spatial regions were used in repeated measures ANOVAs, but spatial effects were only reported if they interacted with the experimental conditions (old[yes], lure[yes], new[no]). The average ERPs

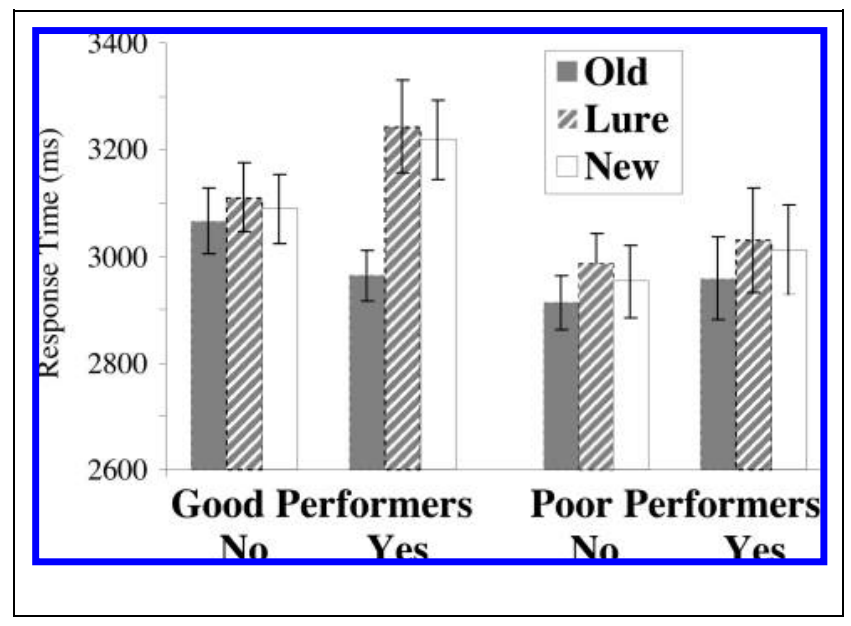

Figure 1. Mean response time (RT) from test-word onset. Good and Poor performers were those above and below the median in discrimination of old items and lures. RTs are separated according to the selected response (no or yes). Error bars show the standard error of the mean. 
Figure 2. Sensor locations on the 128-channel Geodesic Sensor Net. The approximate sensor locations were projected onto a 3-D head model from which these 2-D images were taken. Sensors appear more closely spaced at the edges because depth is lost in the 2-D images, but actual electrode spacing is approximately equidistant throughout. Different symbols are used to denote channels within each of the eight spatial regions used in ANOVAs. Midline electrodes are denoted with diamond-shaped symbols. VR $=$ vertex reference.

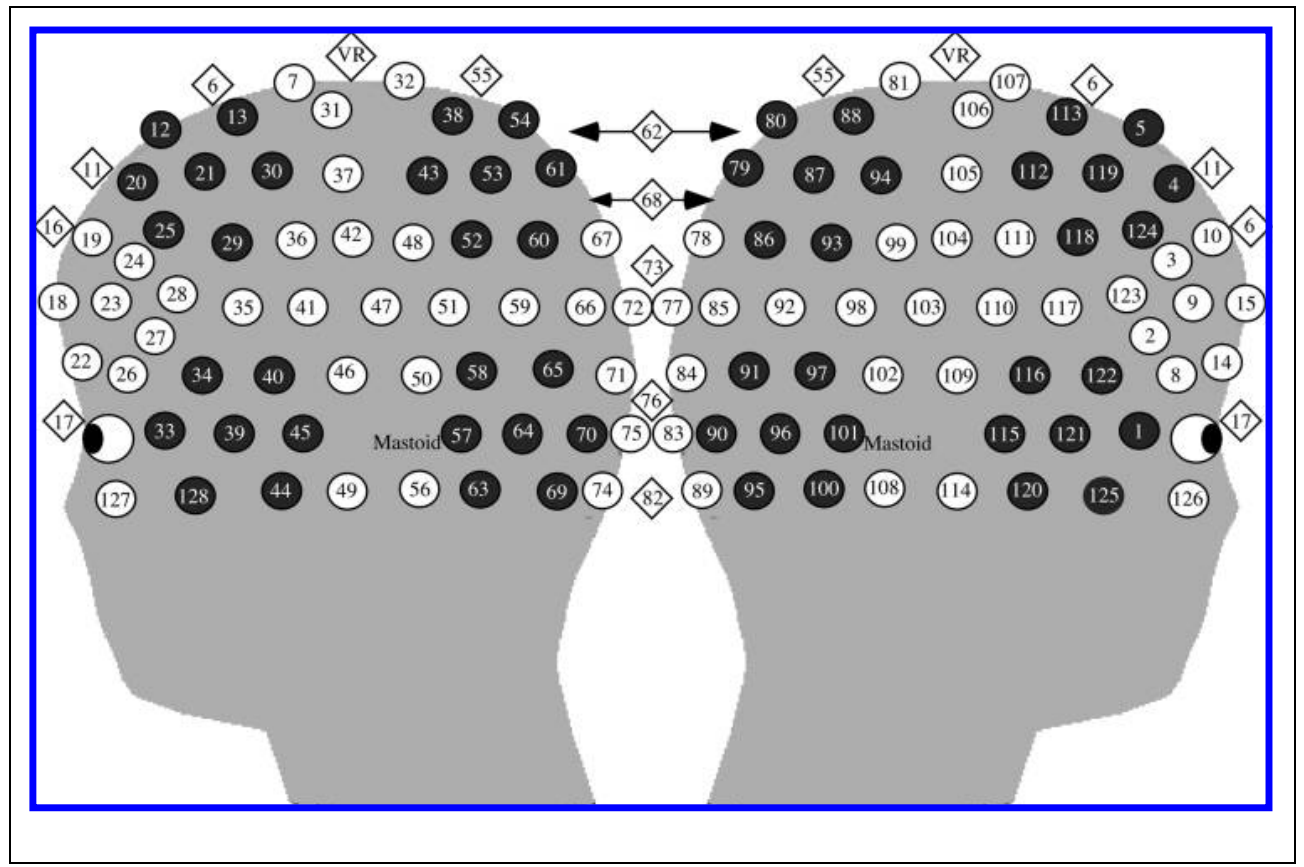

within each region are plotted separately for Good (Figure 3) and Poor (Figure 4) performers. Averaging 128 ERPs into eight waveforms may seem to obviate the use of 128 channels, but for the present purposes, the primary advantage of high-density recording is related to the computation of the average reference. As sampling density increases, the average reference comes closer to approximating the ideal of a reference-independent voltage representation (Dien, 1998).

Analyses focused on the FN400, parietal, and late frontal ERP old/new effects that were reviewed in the Introduction. Locations were selected according to previously published results. Typical mastoid-referenced recordings show the FN400 and parietal old/new effects over superior scalp regions. The FN400 is more negative for new than old stimuli over superior frontal sites (e.g., Rugg, Mark, et al., 1998, Rugg, Walla, et al., 1998). The parietal effect is typically more positive for old than new stimuli over temporoparietal regions (e.g., Allan et al., 1998). However, dipolar effects are expected when the scalp surface is adequately sampled because surfacerecorded potential fields are dipolar with equal positive and negative fields (Nunez, 1981). Previous studies using the same 128-channel recording apparatus and an average-reference have identified consistent dipolar reflections of the FN400 and parietal old/new effects over inferior scalp regions (Curran, 1999; 2000). Anterior, superior FN400 differences (new < old) co-occur with posterior, inferior differences (new $>$ old). Parietal differences (old $>$ new) co-occur with anterior, inferior differences (old $<$ new). Although these effects are more completely described in bipolar terms, we will continue to refer to these effects according to their superior scalp manifestations (i.e., FN400 and parietal old/new effects) to maintain consistency with previous reports in the literature. Mastoid-referenced ERPs are shown in the Appendix to facilitate comparison with other research.

One potential problem with directly comparing ERPs from Good and Poor groups involves varying signal-tonoise ratios attributable to different numbers of trials per ERP (see Table 2). The $t$ tests indicated group differences in the number of old[yes] trials $(p<.01)$, marginal differences in the number of new[no] trials $(p=.09)$, and no difference in lure[yes] trials. An optimal solution to this problem would be to compute ERPs after randomly selecting an equal number of trials for each Group $\times$ Condition. For the old[yes] condition, Poor performers generated $70 \%$ as many trials as the Good performers, so 30\% of the Good performers' trials were dropped. For the new[no] condition, Poor performers generated $88 \%$ as many trials as the Good performers, so $12 \%$ of the Good performers' trials were dropped. Software constraints did not enable random trial selection, so we adopted a slightly different approach. Trials were dropped from the middle test lists, so that the average retention interval would not differ between the groups. The number of trials in the resultant "trial-matched" ERPs did not differ significantly between groups for any condition (Table 2). The following results were derived from the trial-matched ERPs for the old[yes], lure]yes], and new[no] conditions, but the original ERPs were very similar.

\section{FN400 Effects (300-500 msec)}

Curran (2000) found that an FN400 component showed higher amplitude for new words than old words or 
Figure 3. Average-referenced ERPs for Good performers who were above the median in discrimination of old items and lures. Plotted ERPs are channel means within each of the eight spatial regions used for ANOVAs (see Figure 1). LAI = left, anterior, inferior; LAS $=$ left, anterior, superior; LPS $=$ left, posterior, superior; LPI $=$ left, posterior, inferior; RAI $=$ right, anterior, inferior; RAS $=$ right, anterior, superior; RPS = right, posterior, superior; RPI = right, posterior, inferior.

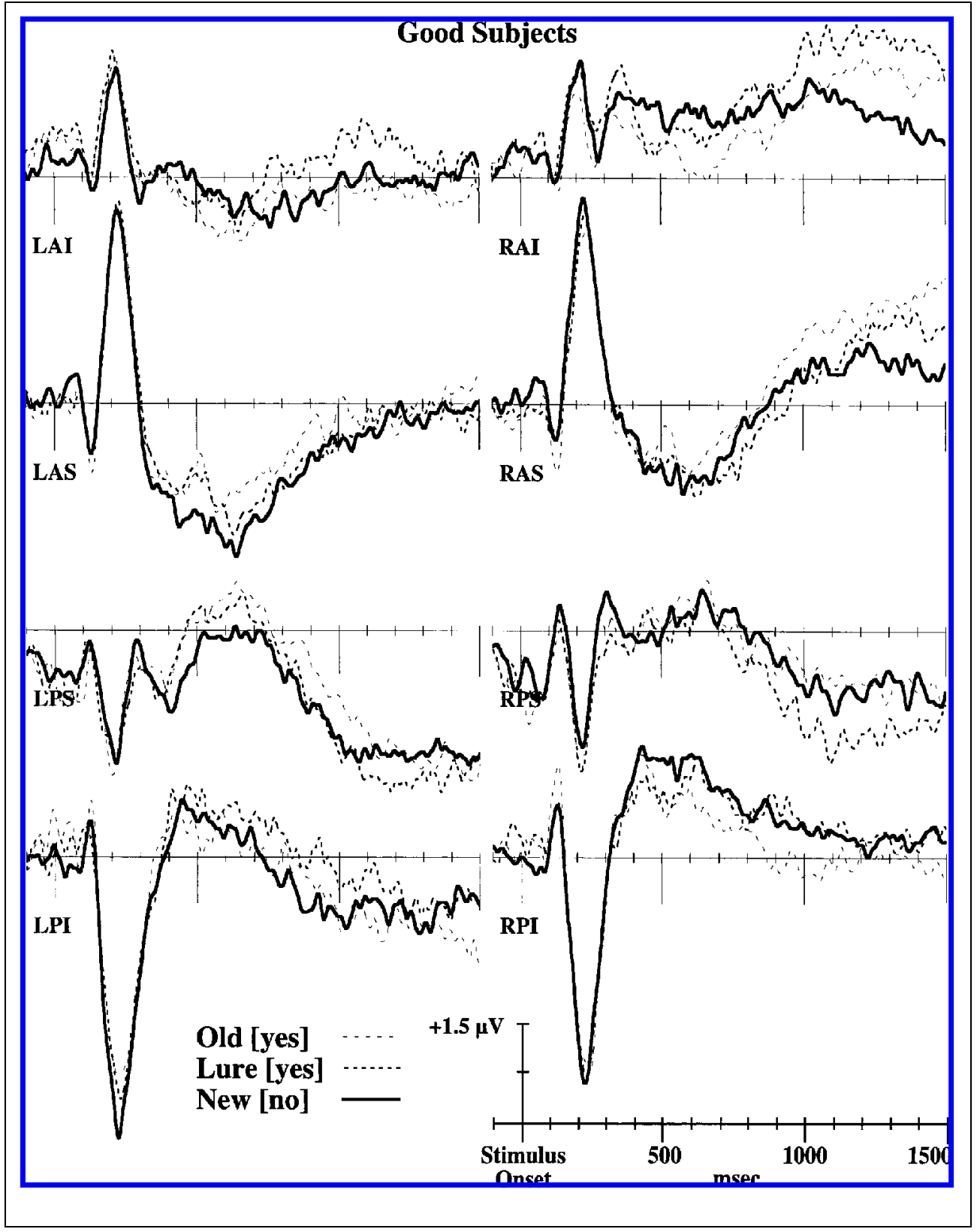

plurality-reversed lures. The FN400 was associated with a dipolar topographic pattern, with negative voltages peaking over anterior, superior regions (AS, new[no] < lure $[$ yes $]=\operatorname{old}[$ yes]) and positive voltages peaking over posterior inferior (PI, new [no] > old[yes] = lure[yes]) We replicated Curran's analysis in a Group (Good, Poor) $\times$ Condition (old [yes], lure[yes], new[no]) $\times$ Location $($ AS, PI) $\times$ Laterality (left, right) repeated measures ANOVA. Only the main effects of location and laterality were significant, and no condition or group effects approached significance.

\section{Parietal Effects (400-800 msec)}

Curran (2000) found that parietal (posterior, superior) ERPs were more positive for old words than lures from
400 to 800 msec (PS, old[yes] > lure[yes]). The negative dipolar reflection of this pattern appeared over anterior, inferior regions (AI, old[yes] < lure[yes]). We replicated Curran's analysis in a Group $\times$ Condition (old[yes], lure [yes]) $\times$ Location (AI, PS) $\times$ Laterality (left, right) ANOVA. The Condition $\times$ Location interaction was significant, $F(1,44)=5.58, M S E=2.87, p<.05$. This interaction replicated Curran's results: ERPs to old words were more positive than ERPs to lures over posterior/superior regions, but old words were more negative than lures over anterior, inferior regions. No group effects or interactions approached significance.

Although the Group $\times$ Condition $\times$ Location interaction was not significant, $F(1,44)=1.15, M S E=2.87$; inspection of Figures 3 and 4 suggest group differences in the Condition $\times$ Location interaction. The Location $x$ 
Figure 4. Average-referenced ERPs for Poor performers who were below the median in discrimination of old items and lures. Plotted ERPs are channel means within each of the eight spatial regions used for ANOVAs (see Figure 1). LAI = left, anterior, inferior; LAS $=$ left, anterior, superior; LPS $=$ left, posterior, superior; LPI $=$ left, posterior, inferior; $\mathrm{RAI}=$ right anterior, inferior; RAS $=$ right, anterior, superior; RPS = right, posterior, superior; RPI $=$ right, posterior, inferior.

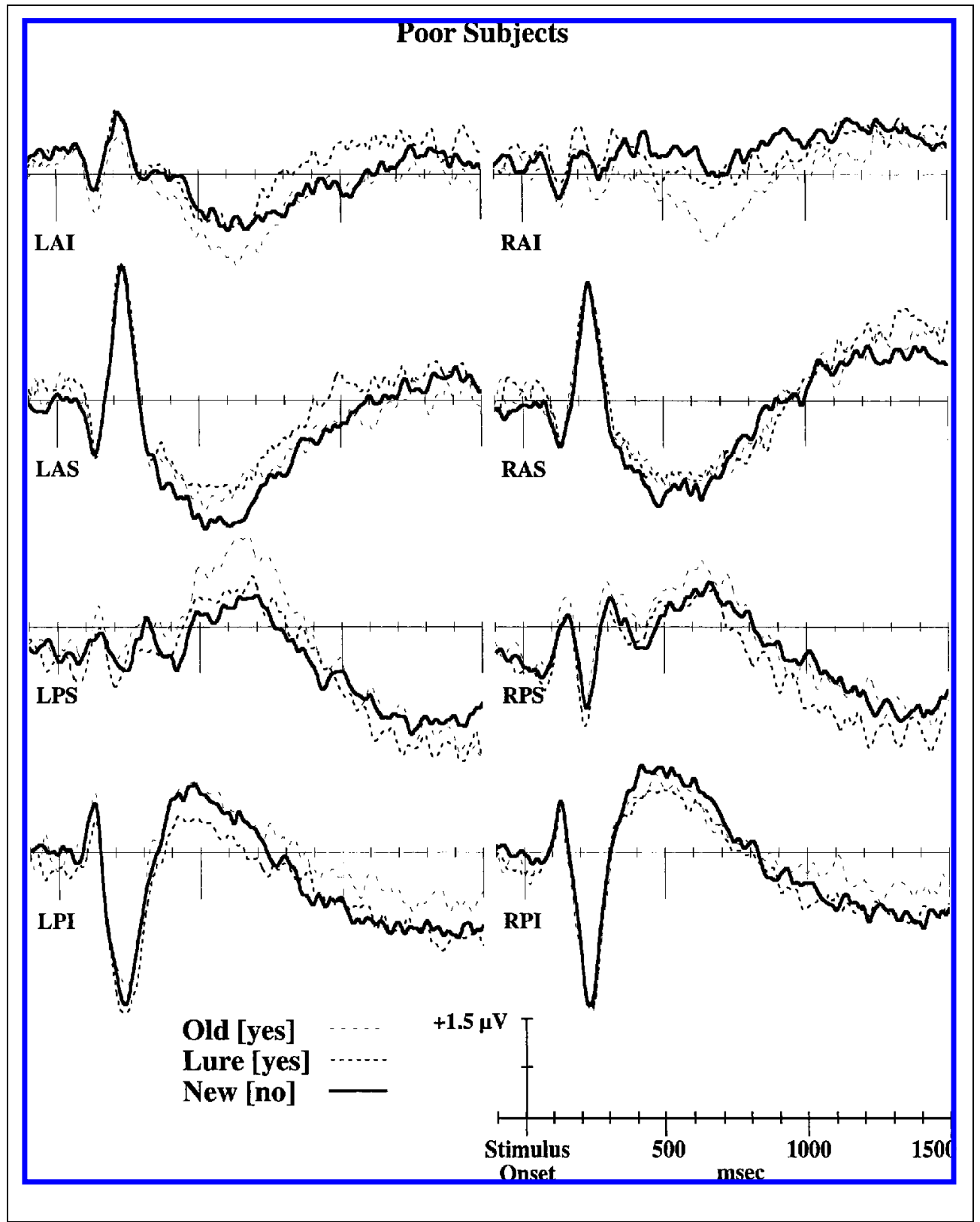

Condition interaction is only visible for Poor performers (most apparent over the LPS and RAI regions). Therefore, separate ANOVAs were computed for each group alone. The condition by location interaction was significant for the Poor performers, $F(1,22)=5.56, M S E=$ $3.01, p<.05$; but not for the Good performers, $F(1,22)$ $<1, M S E=2.72$. The complete topography of the old[yes]-lure[yes] difference can be seen in Figure 5 in which left parietal differences (old[yes] $>$ lure[yes]) and right/anterior/inferior differences (old[yes] < lure [yes]) are more prominent for Poor than for Good performers. Each head model in Figure 5 was constructed by computing differences between conditions (old-lure) for each channel at each temporal sample, interpolating the differences across a spherical head model, averaging the samples within the temporal inter- val (400-800 msec), and projecting the average interpolated image onto a 3-D head model. ${ }^{1}$

Considering the failure to show parietal ERP differences between old and lure ERPs for Good performers, it was important to determine if the standard parietal ERP old/new was obtained by comparing old[yes] and new [no] conditions. The Old/New $\times$ Location interaction was significant for both Good performers, $F(1,22)=4.90, M S E$ $=1.57, p<.05$; and Poor performers, $F(1,22)=6.11$, $M S E=1.62, p<.05$. Thus, the standard parietal ERP old/ new effect was observed for both groups of subjects.

\section{Late Frontal Effects (1000-1500 msec)}

Because of the temporal variability of frontal ERP effects observed in previous studies, the temporal 
Table 2. Mean Number of Trials per ERP per Subject

\begin{tabular}{llllll}
\hline & \multicolumn{2}{l}{ Original ERPs } & & \multicolumn{2}{l}{ Trial-Matched ERPs } \\
\cline { 2 - 3 } & Good & Poor & & Good & Poor \\
\hline Old[yes] & 54.00 & 40.43 & 36.96 & 40.43 \\
Lure[yes] & 37.78 & 40.26 & 37.78 & 40.26 \\
New[no] & 60.22 & 52.83 & & 52.43 & 52.83 \\
\hline
\end{tabular}

window for the present analyses was chosen from visual inspection of the ERPs (1000-1500 msec). Only anterior regions were included in a Group $\times$ Condition (old[yes], lure[yes], new[no]) $\times$ Location (inferior, superior $) \times$ Hemisphere ANOVA. The condition main effect approached significance, $F(2,88)=3.05, M S E=$ 2.38, $p=.06$. Group interacted with location and hemisphere, $F(1,44)=4.71, M S E=.78, p<.05$. No other effects approached significance.

Although group and condition did not interact significantly in the initial analyses, inspection of the ERPs suggested that condition effects may have existed for only the Good performers. Therefore, separate ANOVAs were computed for each group. The Condition $\times$ Hemi- sphere interaction was significant for Good performers, $F(2,44)=4.30, M S E=.69, p<.05$; but not for Poor performers, $F(2,44)<1, M S E=1.19$. Post hoc analyses focused on the pairwise differences between right anterior ERPs from Good performers (all $d f=1,44 ; M S E=$ .69). ERPs in both old[yes] $(F=15.59, p<.001)$ and lure[yes] $(F=16.98, p<.001)$ category were more positive than ERPs in the new[no] category. Voltage did not differ between old[yes] and lure[yes] $(F<1)$.

The foregoing analysis indicated that right frontal ERPs were more positive when Good performers responded "yes" to old words or lures than when they correctly responded "no" to new items. Because this pattern could be attributable to trivial differences between "yes" and "no" responding, this possibility was addressed in further analyses including ERPs associated with "no" responses to lures. ${ }^{2}$ Paired $t$ tests were used to compare Good performers' right/anterior voltages in the lure[yes] $(\mathrm{MN}=1.50 \mu \mathrm{V})$, lure[no] $(\mathrm{MN}=1.40$ $\mu \mathrm{V})$, and new $[\mathrm{no}](\mathrm{MN}=0.79 \mu \mathrm{V})$ conditions. Mean voltages were more positive for lure[no] than new[no] conditions; $t(22)=2.12, S E=.29, p<.05$ (two-tailed); but lure[no] and lure[yes] conditions did not differ, $t(22)=0.23, S E=.41$. Consistent differences also were

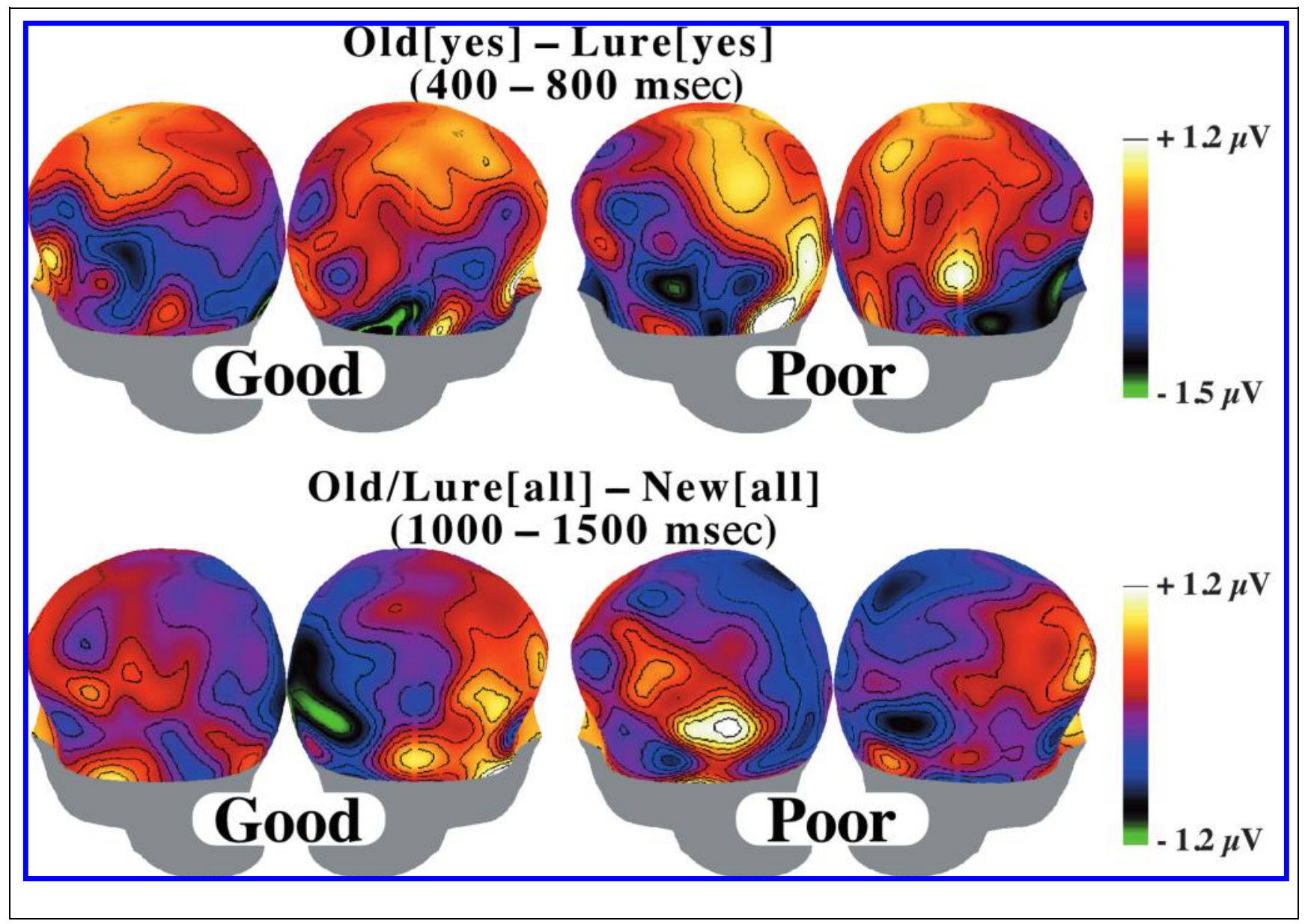

Figure 5. Topographic distributions of primary ERP differences between conditions. Top: Contours lines are plotted every $0.225 \mu \mathrm{V}$. Bottom: Contours lines are plotted every $0.20 \mu \mathrm{V}$. 
observed when ERPs were unconditionally averaged without regard to response choice (old[all], lure[all], new[all]). Good performers' unconditionally averaged right frontal ERPs were more positive for old[all] (MN $=0.52 \mu \mathrm{V})$ than new [all] $(\mathrm{MN}=-0.04 \mu \mathrm{V})$ conditions, $t(22)=2.66, S E=.19, p<.05$; and more positive for lure[all] $(\mathrm{MN}=0.56 \mu \mathrm{V})$ than new[all] conditions, $t(22)$ $=3.53, S E=.16, p<.01$. Mean right, frontal voltages did not significantly differ between lure[all] and old[all] ERPs, $t(22)=0.24, S E=.17$. Thus, right frontal differences between conditions were not related to response choice. Figure 5 (bottom) shows the topography of the late frontal differences by subtracting the new[all] voltages from the averaged old[all] and lure [all] voltages.

\section{DISCUSSION}

ERPs were recorded during the test phase of the DRM paradigm. Good and Poor performers were identified from their behavioral discrimination between studied targets and similar lures. The primary result was that only the Good performers showed a right frontal old/ new effect (1000-1500 msec), and this effect was similar to the lure/new difference. Poor performers showed no late frontal differences between conditions. A number of functional imaging studies have debated possible right frontal contributions to functions related to retrieval effort, retrieval attempt, or retrieval success (reviewed by Schacter, Buckner, \& Koutstaal, 1998). The Poor spatial resolution of ERPs does not allow us to decisively link the present right frontal ERP effects to functional activations localized with PET or fMRI. However, it is useful to consider if processes related to effort, attempt, or success are consistent with our ERP results. One hallmark feature taken to indicate retrieval success is differential activation between old and new items (e.g., Rugg, Fletcher, Chua, \& Dolan, 1999; Buckner, Koutstaal, Schacter, Dale, et al., 1998; Buckner, Koutstaal, Schacter, Wagner, \& Rosen, 1998). According to this criterion, the frontal ERPs are not indicative of retrieval success because they did not differ between true recognition of old items and false recognition of lures. Furthermore, when all trials were considered without conditionalizing on accuracy, Good performers showed more positive right frontal ERPs for old item and lures than for new items. Although right frontal ERPs did not differ according to the accuracy of individual trials, they did differentiate between subjects who were more or less accurate on average. In this regard, the right frontal ERPs may be related to more strategic retrieval and evaluation processes.

Previous interpretations of the right frontal ERP old/ new effect suggested they reflect evaluation processes that may include more strategic retrieval efforts or attempts (Wilding \& Rugg, 1997a, 1997b; Wilding, 1999; Allan et al., 1998; Johnson et al., 1996). Frontal activations from functional imaging studies of the DRM paradigm has been interpreted similarly (Schacter, Reiman, et al., 1996; Schacter, Buckner, et al., 1997). The late time course of the ERP effect is consistent with processes that occur after initial retrieval generated by the test probe (e.g., Johnson et al., 1996 and as also indicated by event-related fMRI, Schacter, Buckner, et al., 1997). By this account, Good performers showed better discrimination between old words and lures because they were more likely to carefully evaluate activated information or attempt additional retrieval before making a response. The observation that only Good performers were slower for correct than incorrect responses is consistent with the idea that Good performers were responding more carefully. Wilding (1999) similarly found that right frontal ERP amplitude was higher for conditions associated with slow responding. Previous behavioral results have shown that warning subjects to respond cautiously can slightly reduce false recognition in the DRM paradigm (McDermott \& Roediger, 1998; Gallo, Roberts, \& Seamon, 1997).

It appeared that any such postretrieval evaluation processes were engaged primarily when subjects encountered old items or lures. Evaluation may be contingent on high familiarity or other information that was more readily retrieved for old items or lures than new items. A similar interpretation was offered to explain right prefrontal activation obtained in an event-related fMRI study using the remember-know paradigm (Henson, Rugg, Shallice, Josephs, \& Dolan, 1999). Right frontal activity associated with "know" judgments was greater for old than new words, but such differences were absent for "remember" judgments. Henson et al. (1999) suggested that frontal monitoring processes may be required for choosing to respond "know" or "new" to a familiar word, but may not be necessary when the spatio-temporal context of the study episode is clearly "remembered."

The conclusion that right frontal evaluation processes may be a primary factor differentiating subjects who are Good versus Poor at discriminating studied targets from lures is consistent with neuropsychological studies of recognition memory. A case study of a patient with right frontal lobe damage (BG) revealed extraordinarily high false alarm rates on standard recognition memory tests (Curran et al., 1997; Schacter, Curran, et al., 1996). Signal detection analyses indicated that BG had a discrimination deficit as well as showing an abnormally liberal response bias (Curran et al., 1997). Liberal response biases have also been reported for older subjects with high false alarm rates to similar lures (Kensinger \& Schacter, 1999; Koutstaal \& Schacter, 1997). Similarly, Poor performers showed a statistically marginal $(p=$ .07) trend towards responding more liberally than Good performers in the present experiment. These differences in response bias are again consistent with the idea that 
Good performers were responding more carefully than Poor performers. Numerous other studies have confirmed that frontal brain injury can lead to abnormally high false alarm rates (Rapcsak, Reminger, Glisky, Kaszniak, \& Comer, 1999; Parkin, Bindschaedler, Harsent, \& Metzler, 1996; Parkin, Ward, Bindschaedler, Squires, \& Powell, 1999; Delbecq-Derouesné, Beauvois, \& Shallice, 1990), and one study has specifically observed high false alarm rates for frontal-lobe patients in the DRM paradigm (Melo, Winocur, \& Moscovitch, 1999). Whereas these neuropsychological studies have shown that people with frontal damage have high rates of false recognition, the present study is the first to show that people with high levels of frontal activity have relatively low false alarm rates to similar lures.

The parietal ERP old/new effect (400-800 msec) has also been related to the recollection of details (e.g., Curran, 2000; Allan et al., 1998). For example, the parietal old/new effect is larger for "remembering", than "knowing" (Rugg, Schloerscheidt, et al., 1998; Düzel et al., 1997; Smith, 1993), and larger for words studied under deep than shallow encoding conditions (Rugg, Mark, et al., 1998; Rugg, Walla, et al., 1998; Paller \& Kutas, 1992; Paller, Kutas, \& McIsaac, 1995). Both Good and Poor performers exhibited the standard parietal ERP old/new effect (400-800 msec). Surprisingly, only the subjects with Poor behavioral discrimination between old items and lures exhibited more positive parietal voltages when subjects responded "yes" to old items than to lures (and corresponding inferior, anterior voltages were more negative for true than false recognition). This inverse relationship between the behavioral and ERP results clearly suggests that processes underlying the parietal ERP effects were not responsible for accuracy differences between the Good and Poor groups. This finding was unexpected, but we will offer a potential explanation.

Discrimination between targets and lures could benefit from either high quality retrieval or from careful postretrieval evaluation (e.g., Johnson \& Raye, 1981). We have argued that Good performers' accuracy benefited from better evaluation, as indexed by the late frontal ERP effects. Following previous interpretations of old/new parietal differences, one interpretation of parietal differences between true recognition of old words and false recognition of lures would be that more detailed, higher quality information is associated with true than false recognition. Such an interpretation fits behavioral evidence that recollection of perceptual details is more prevalent for true than false recognition (Mather et al., 1997; Norman \& Schacter, 1997).

Post hoc $t$ tests suggested that parietal ERP differences (400 to $800 \mathrm{msec}$ ) between Good and Poor performers were confined to the old[yes] condition. Parietal old/ lure differences were originally assessed in a 2 Group $\times$ 2 Condition $\times 2$ Laterality $\times 2$ Location (AI, PS) ANOVA.
Between-group $t$ tests were computed in each of the eight possible cells $(2$ Condition $\times 2$ Laterality $\times 2$ Location). Left/posterior/superior voltages in the old [yes] condition were more positive for Poor than Good performers, whereas right/anterior/inferior voltages in the old[yes] condition were more negative for Poor than Good performances (both $p<.05$ ). No other group comparisons were significant (all $p>.10$ ).

If parietal voltages index the quality of retrieved information, why would old[yes] amplitudes be higher for Poor than Good performers? One explanation may follow from the fact that old[yes] ERPs are conditionalized on accurate performance. Assume that the quality of retrieved information was similar for Good and Poor performers. Old items associated with low retrieval would be more often recognized by Good than Poor performers because of better postretrieval evaluation. Thus, when averaging is conditionalized on accuracy, Good performers' ERPs should include more low-quality trials than Poor performers' ERPs. If the average quality of information associated with the old[yes] condition was higher for Poor than Good performers, parietal amplitudes would be higher for Poor performers. This explanation receives some support from the insignificant group differences obtained when the eight betweengroup $t$ tests $(2$ Condition $\times 2$ Laterality $\times 2$ Location, 400-800 $\mathrm{msec}$ ) were repeated on ERPs not conditionalized on accuracy (old[all], lure[all], all $p>.10$ ).

The retrieval quality interpretation is consistent with the hypothesis that the parietal ERP old/new effect arises from medial temporal lobe activity (Düzel et al., 1999) or cortico-hippocampal interactions (Rugg, Walla, et al., 1998; Wilding \& Rugg, 1996). Although MTL activity has been observed somewhat inconsistently in functional imaging studies, obtained MTL activations have been regularly related to retrieval success (reviewed by Schacter, Buckner, et al., 1998). Theoretically, the MTL contribution to conscious recollection has been related to the retrieval of high quality information (O'Reilly et al., 1998). Further research will be needed to clarify the origin of the somewhat paradoxical parietal old/lure differences observed for Poor but not Good performers.

Other analyses focused on the FN400 ERP old/new effect (400-800 msec). N400-like ERP old/new effects have been consistently described in the literature (typically having a centro-parietal maximum, reviewed by, Rugg, 1995). More recent research has identified a frontally maximal N400-like old/new effect that Curran (1999, 2000) dubbed the "FN400." The FN400 has been associated with the familiarity component of dual-process recognition memory theories (Curran, 1999, 2000; Rugg, Mark, et al., 1998, Rugg, Walla, et al., 1998). Düzel et al.'s (1997) previous ERP experiment with the DRM paradigm identified an FN400-like old/new effect that was similar for true and false recognition, but was more temporally located. We expected to 
replicate the standard FN400 old/new effect in the present experiment in addition to expecting no differences between similarly familiar old and lure conditions. However, no FN400 differences were observed between the conditions.

There are two primary differences between the present experiment and those that have clearly found FN400 old/new effects (Curran, 1999, 2000; Rugg, Mark, et al., et al., 1998, Rugg, Wallam, et al., 1998). First, both study and test modalities were visual in past experiments, whereas auditory study was followed by visual test in the present experiment. Although semantic familiarity clearly influences performance in the DRM paradigm, it is possible that the FN400 indexes perceptual familiarity or perceptual fluency (e.g., Jacoby, 1996; Johnston, Dark, \& Jacoby, 1985). For example, an ERP study of immediate and nearby (five intervening items) word repetition effects identified a frontal N400-like component that responded to within-modality, but not cross-modality repetition (Rugg \& Nieto-Vegas, 1999). Düzel et al. (1997) observed an N400 old/new effect in the DRM paradigm when both study and test modalities were visual. If the FN400 is not sensitive to semantic familiarity, this would be a further indication that it represents a qualitatively different component than the centro-parietal N400 that clearly is sensitive to semantic context (reviewed by Kutas \& Van Petten, 1994). Second, previous experiments have used two to six shorter study-test blocks rather than the present procedure of presenting a single, long study list followed by a single, long test list. This single study-test block makes the average retention interval longer in the present (approximately $30 \mathrm{~min}$ ) than previous experiments. Rugg (1995) has observed that standard centroparietal N400 old/new effects can be eliminated by long retention intervals. On the other hand, Düzel et al. observed an N400 old/new effect in the DRM paradigm after a retention interval greater than $30 \mathrm{~min}$. Future studies will need to more systematically manipulate study-test modality and retention interval to assess the sensitivity of the FN400 to these variables.

In conclusion, these results add to the existing body of evidence indicating that the parietal and frontal ERP old/new effects reflect dissociable memory processes. As in previous research (reviewed by Allan et al., 1998), these memory-related ERP effects responded differently to the experimentally manipulated variables. The present research further shows that these components are differentially related to behavioral performance. We have argued that right frontal old/new effect reflects a postretrieval evaluation process that was more readily engaged by subjects with good behavioral discrimination between true and false recognition. We also speculated that the absence of a parietal old/lure effect for Good performers (and the presence of an old/lure effect for Poor performers) might reflect the fact that better evaluation processes of Good performers facilitate their recognition of old targets with relatively low quality information.

\section{METHOD \\ Subjects}

Fifty-three undergraduate students from Case Western Reserve University participated in the experiment. Subjects participated to fulfill an introductory psychology research requirement or were paid US $\$ 15$. All subjects were right-handed and native English speakers. Forty-six subjects were included in the reported analyses. The data from seven subjects were discarded because of an insufficient number of artifact-free trials.

\section{Stimuli}

The stimuli were used in a previous ERP study (Düzel et al., 1997). The study list contained 288 words grouped into 24 sets of 12 semantic associates (e.g., winter, ice, wet, frigid, chilly, heat, weather, hot, air, shiver, arctic, frost). The semantic sets were common associates of a nonstudied theme word (e.g., cold). The test list contained 288 words with 96 from each of three conditions: old, lure, and new. Old words were heard on the study list (four from each semantic set). Lures were semantic associates of studied words that were not heard on the study list (four per category; e.g., cold, freeze, snow, warm). New words were not studied and not obvious semantic associates of the studied words. Two additional semantic sets were used for practice along with four unrelated words.

To maximize the number of lures tested, stimuli differed from similar studies (e.g., Johnson et al., 1997; Schacter, Reiman, et al., 1996; Roediger \& McDermott, 1995). First, most studies have tested only a single "critical lure" from each semantic set (e.g., cold) rather than four lures per set. Second, words were not counterbalanced through the conditions. Counterbalancing would have reduced the number of potential observations per subject because each subject could not have studied all semantic sets. Old, lure, and new words were balanced for length (4-8 letters) and word frequency $(\mathrm{MN}=76$ occurrences per million, Kucera \& Francis, 1967) to minimize item effects. Testing many items per condition (96) also tends to minimize item effects. Furthermore, item confounds cannot explain condition effects that varied between Good and Poor performers.

Stimulus presentation and response collection were controlled by a Macintosh computer. Auditory study words were digitally recorded in a single, female voice and presented by an external speaker. Visual test words were presented centrally on a 14-in. Apple Multiscan Color Monitor. Stimuli (12-point Geneva font) subtended approximate visual angles of $1.3^{\circ}$ to $2.6^{\circ}$ (hor- 
izontally) and $0.6^{\circ}$ (vertically) from a viewing distance of $45 \mathrm{~cm}$.

\section{Design and Procedure}

Each 2-hr experimental session began with instructions and a practice phase (24 study words and 12 test words) prior to application of the Geodesic Sensor Net. Subjects were instructed to memorize each word heard on the study list. The presentation rate was $1.5 \mathrm{sec}$ per word. Each semantic set was preceded by a "knock-knock" sound and followed by a 5-sec pause. Subjects were given 30 -sec rest breaks after sets 8 and 16. The study list was followed by a break of approximately 5 min during which resting EEG was visually inspected, electrodes were adjusted, and subjects were reminded of the testing procedures.
The test list was divided into 12-trial subsets containing four words per condition and no more than one word per semantic set. Each subset began with a visual instruction to "please sit still" for 5 sec. Subjects were given a self-paced rest break after each subset.

Each test trial event was temporally synched to the refresh cycle of the display monitor (15 msec/cycle). A trial began with a variable duration (525-1005 msec) central plus sign. The plus was replaced by the test word for 1,995 msec then replaced by a central question mark. The question mark remained on the screen until the subject pressed a response key. An asterisk appeared after the response and remained visible throughout the 2-sec interstimulus interval. EEG recording began 495 msec prior to word onset and lasted for 2,000.

Subjects were asked to press a "yes" key for words that were heard on the study list and a "no" key for

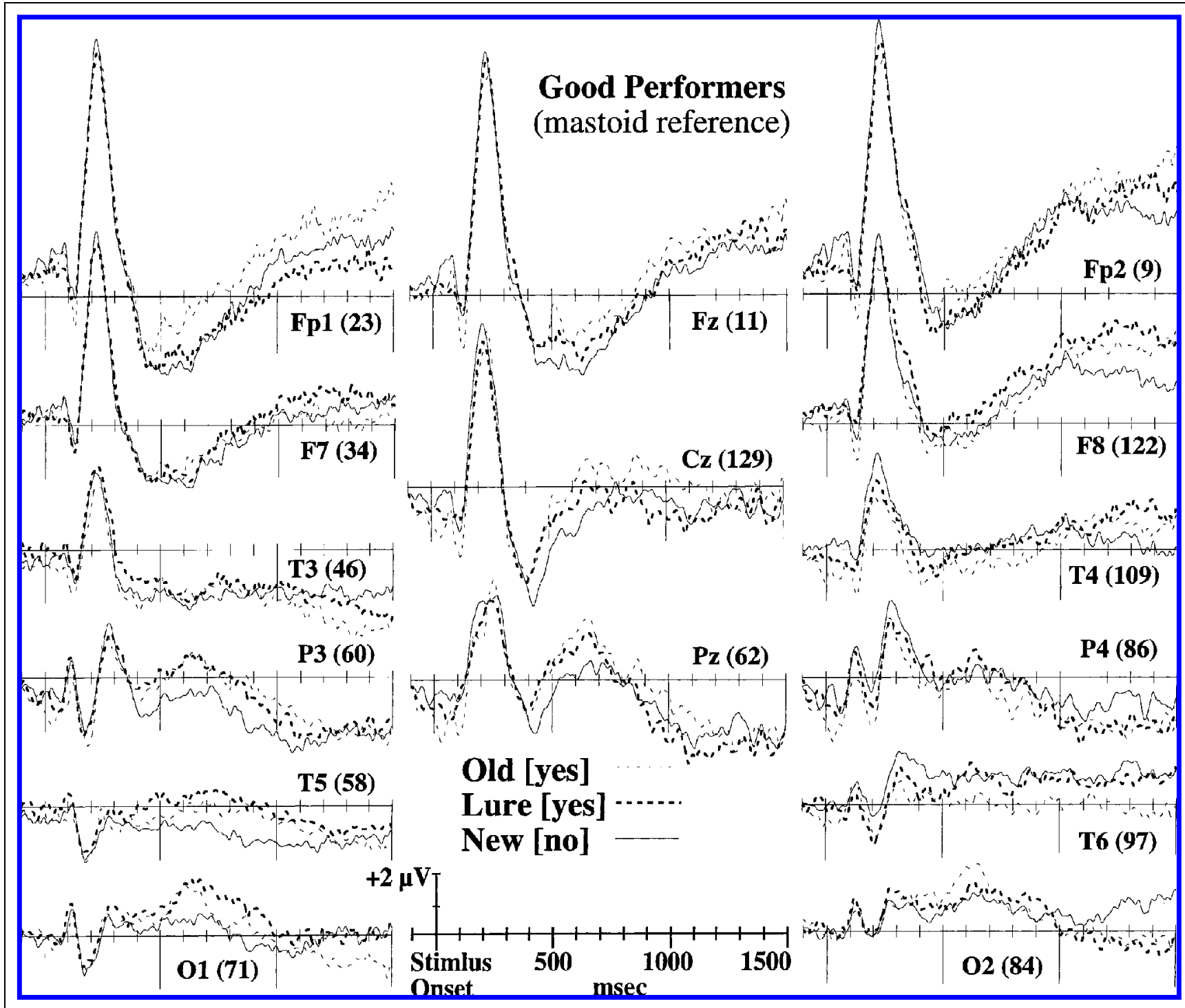

Figure 6. Mastoid-referenced ERPs for Good performers who were above the median in discrimination of old items and lures. Each channel is identified by its nearest $10-20$ system label along with parenthetical numbers corresponding to the sensor numbers in Figure 1 . 
words that were not previously heard. Key presses were made with the first two fingers of the right hand, and left/right to yes/no assignments were counterbalanced across subjects. Subjects were instructed to wait for a question mark before responding, to remain as motionless as possible, and to minimize eye blinks.

\section{EEG Recording}

Scalp voltages were collected with a 128-channel Geodesic Sensor Net ${ }^{(i m}$ (Tucker, 1993) connected to an AC-coupled, 128-channel, high-input impedance amplifier (200 M $\Omega$, Net Amps ${ }^{(\mathbb{I})}$, Electrical Geodesics, Eugene, OR). Amplified analog voltages (0.1-100 Hz bandpass) were digitized at $250 \mathrm{~Hz}$. Recorded voltages were referenced to a vertex electrode. Individual electrodes were adjusted until impedances were less than $50 \mathrm{k} \Omega$.

\section{EEG Data Reduction}

Trials were dropped from analyses if they contained eye movements (eye channel differences greater than $70 \mu \mathrm{V}$ ) or more than five bad channels (changing more than $100 \mu \mathrm{V}$ between samples, or reaching amplitudes over $200 \mu \mathrm{V}$ ). Data from individual channels that were consistently bad for a given subject were replaced using a spherical interpolation algorithm (Srinivasan, Nunez, Silberstein, Tucker, \& Cadusch, 1996). The median number of replaced channels/subject was 1.00 (mode $=0$, range $=0$ to 5). Data from seven subjects were removed because there were less than 16 Good trials in which they

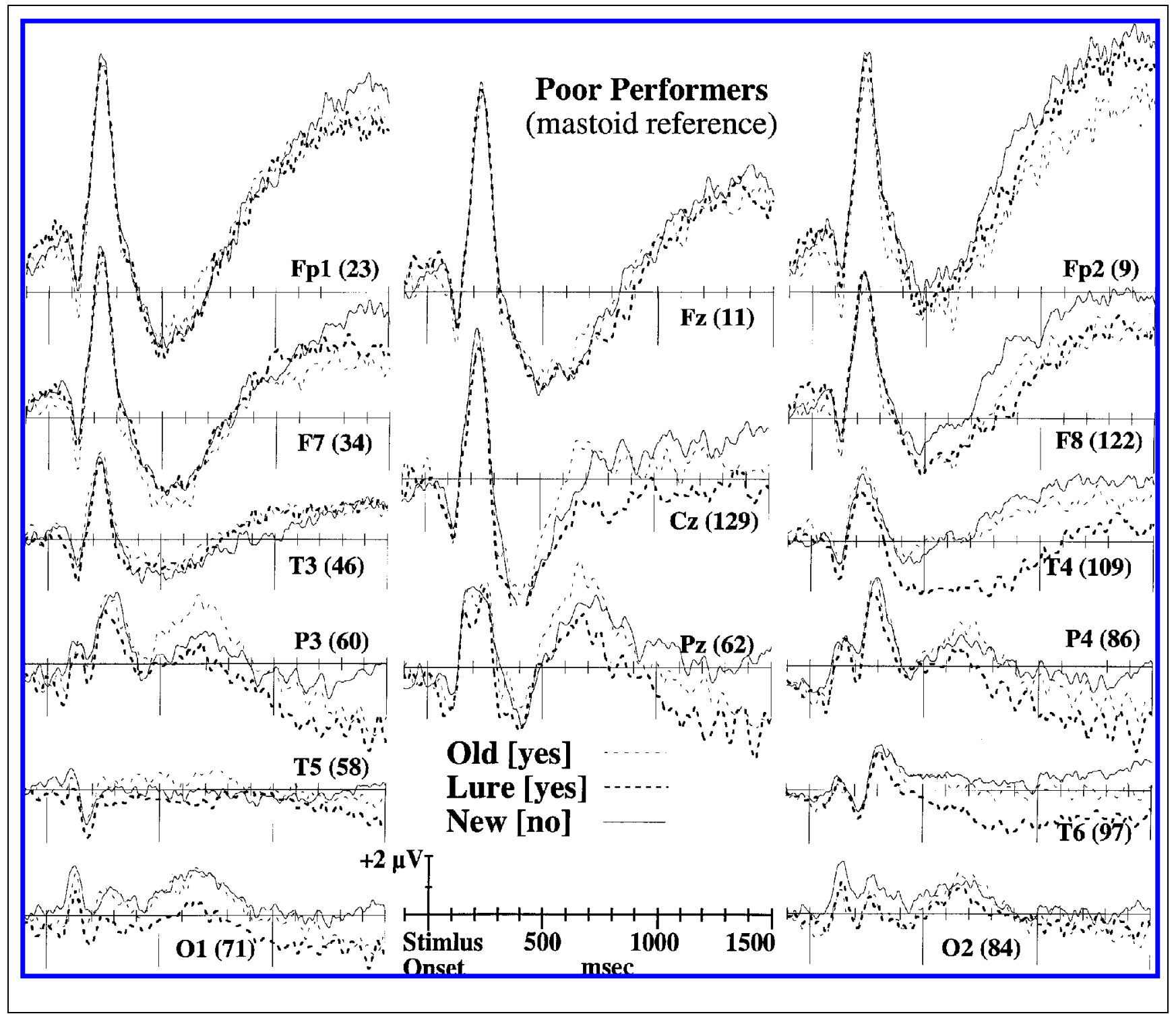

Figure 7. Mastoid-referenced ERPs for Poor performers who were below the median in discrimination of old items and lures. Each channel is identified by its nearest 10-20 system label along with parenthetical numbers corresponding to the sensor numbers in Figure 1 . 
responded "yes" to lures, thus 46 subjects were included in the analyses.

\section{Appendix}

The ERPs were re-references with respect to the average of the two mastoid channels to facilitate comparison with mastoidreferenced ERPs reported in the literature. Figures 6 (Good performers) and 7 (Poor performers) show the mastoid-referenced ERPs for 15 electrodes that were nearest to the standard 10-20 system locations (Jasper, 1958). The primary results from the average-reference analyses are also apparent in the mastoid-referenced ERPs. First, the parietal ERP old/new effect (which is typically left lateralized) can be seen at the P3 location. Only Poor performers showed more positive amplitudes for old[yes] than lure[yes] conditions at P3 (most apparent between 500 and $800 \mathrm{msec}$ ). Second, Good performers' late, right frontal (Fp2 and F8, 1000-1500 msec) amplitudes were more positive for lures and old items compared to new items. Poor performers showed some right frontal differences, but these were not consistent across channels.

\section{Acknowledgments}

The present research was supported by a W.P. Jones Faculty Development Award from CWRU, a Research Initiation Grant from CWRU, a grant from the McDonnell-Pew Program in Cognitive Neuroscience, NIA grants AG08441, AG09253, AG15793, and NIMH grant NS60941. Thanks to A. Daggy, P. Drocton, A. David, J. Hinman, A. Hills, J. Johnson, S. Klein, D. Marquardt, K. Raymond, J. Ream, D. Scott, M. Smith, and J. Teichman for research assistance; Electrical Geodesics for technical support; and Andy Yonelinas for sharing his word lists.

Reprint requests should be sent to Tim Curran, Department of Psychology, University of Colorado, Campus Box 345, Boulder, CO 80309-0345. E-mail: tcurran@psych.colorado.edu.

\section{Notes}

1. The greatest positive difference between old[yes] and lure[yes] can be seen over left/posterior/inferior scalp regions in Figure 5 (white region for Poor performers). This difference is much more inferior than the typical parietal old/new effect, and voltages did not differ between old[yes] and new[no] conditions in this region (see LPI region in Figure 4). Thus, this inferior difference is distinct from the more superior parietal old/new effect (old[yes] > lure[yes] > new[no], for Poor performers).

2. There were insufficient old trials with "no" responses for reliable ERPs to be obtained from this condition.

\section{REFERENCES}

Allan, K., Wilding, E. L., \& Rugg, M. D. (1998). Electrophysiological evidence for dissociable processes contributing to recollection. Acta Psvchologica. 98, 231-252.

Arndt, J., \& Hirshman, E. (1998). True and false recognition in MINERVA2: Explanations from a global matching perspective. Journal of Memorv and Language. 39, 371-391.

Balota, D. A., Cortese, M. J., Duchek, J. M., Adams, D., Roediger, H. L., III, McDermott, K. B., \& Yerys, B. E. (1999). Veridical and false memories in healthy older adults and in dementia of the Alzheimer's type. Cognitive Neuropsychology, 16, 361-384.
Bertrand, O., Perin, F., \& Pernier, J. (1985). A theoretical justification of the average reference in topographic evoked potential studies. Electroencephalography and Clinical Neuroscience. 62, 462-464.

Brainerd, C. J., Reyna, V. F., \& Kneer, R. (1995). False-recognition reversal: When similarity is distinctive. Iournal of Memorv and Lanquage. 34, 157-185.

Buckner, R. L., Koutstaal, W., Schacter, D. L., Dale, A. M., Rotte, M., \& Rosen, B. R. (1998). Functional-anatomic study of episodic retrieval: II. Selective averaging of event-related fMRI trials to test the retrieval success hypothesis. Neuroimage. 7, 163-175.

Buckner, R. L., Koutstaal, W., Schacter, D. L., Wagner, A. D., \& Rosen, B. R. (1998). Functional-anatomic study of episodic retrieval using fMRI: I. Retrieval effort versus retrieval success. Neuroimage. 7, 151-162.

Clark, S. E., \& Gronlund, S. D. (1996). Global matching models of recognition memory: How the models match the data. Psychonomic Bulletin and Review, 3, 37-60.

Curran, T. (1999). The electrophysiology of incidental and intentional retrieval: ERP old/new effects in lexical decision and recognition memory. Neuropsychologia. 37, 771-785.

Curran, T. (2000). Brain potentials of recollection and familiarity. Memory and Cognition, 28, 923-938.

Curran, T., Schacter, D. L., Norman, K. A., \& Galluccio, L. (1997). False recognition after a right frontal lobe infarction: Memory for general and specific information. Neuropsvchologia. 35, 1035-1049.

Curran, T., Tucker, D. M., Kutas, M., \& Posner, M. I. (1993). Topography of the N400: Brain electrical activity reflecting semantic expectation. Electroencephalography and Clinical Neurophysiologv. 88, 188-209.

Deese, J. (1959). On the prediction of occurrence of particular verbal intrusions in immediate recall. Journal of Experimental Psvchology. 58, 17-22.

Delbecq-Derouesné, J., Beauvois, M. F., \& Shallice, T. (1990). Preserved recall versus impaired recognition. Brain. 113, 1045-1074.

Dien, J. (1998). Issues in the application of the average reference: Review, critiques, and recommendations. Behavior Research Methods, Instruments and Computers, 30, 34-43.

Donaldson, D. I., \& Rugg, M. D. (1998). Recognition memory for new associations: Electrophysiological evidence for the role of recollection. Neuropsychologia. 36, 377-395.

Donaldson, D. I., \& Rugg, M. D. (1999). Event-related potential studies of associative recognition and recall: Electrophysiological evidence for context dependent retrieval processes. Brain Research, 8, 1-16.

Donaldson, W. (1992). Measuring recognition memory. Journal of Experimental Psychology: General, 121, 275-277.

Donaldson, W. (1996). The role of decision processes in remembering and knowing. Memory and Cognition, 24, 523-533.

Düzel, E., Cabeza, R., Picton, T. W., Yonelinas, A. P., Scheich, H., Heinze, H. J., \& Tulving, E. (1999). Task-related and itemrelated brain processes of memory retrieval. Proceedings of the National Academy of Sciences, U.S.A. 96, 1794-1799.

Düzel, E., Yonelinas, A. P., Mangun, G. R., Heinze, H. -J., \& Tulving, E. (1997). Event-related potential correlates of two states of conscious awareness in memory. Proceedings of the National Academy of Sciences, U.S.A. 94, 5973-5978.

Gallo, D. A., Roberts, M. J., \& Seamon, J. G. (1997). Remembering words not presented in lists: Can we avoid creating false memories? Psychonomic Bulletin and Review, 4, 271-276.

Gardiner, J. M., \& Java, R. I. (1993). Recognising and remembering. In A. F. Collins, M. A. Gathercole, M. A. Conway, \& P. E. Morris (Eds.), Theories of memory (pp. 163188). Hove: Erlbaum. 
Gillund, G., \& Shiffrin, R. M. (1984). A retrieval model for both recognition and recall. Psychological Review, 91, 1-67.

Henson, R. N., Rugg, M. D., Shallice, T., Josephs, O., \& Dolan, R. J. (1999). Recollection and familiarity in recognition memory: An event-related functional magnetic resonance imaging study. Journal of Neuroscience, 19, 3962-3972.

Hintzman, D. L. (1988). Judgments of frequency and recognition memory in a multiple-trace memory model. Psvchological Review, 95, 528-551.

Hintzman, D. L., \& Curran, T. (1994). Retrieval dynamics of recognition and frequency judgments: Evidence for separate processes of familiarity and recall. Journal of Memory and Language. 33, 1-18.

Hintzman, D. L., \& Curran, T. (1995). When encoding fails: Instructions, feedback, and registration without learning. Memory and Cognition, 23, 213-226.

Hintzman, D. L., Curran, T., \& Oppy, B. (1992). Effects of similarity and repetition on memory: Registration without learning? Journal of Experimental Psychology: Learning, Memory, and Cognition, 18, 667-680.

Hirshman, E., \& Master, S. (1997). Modeling the conscious correlates of recognition memory: Reflections on the remember-know paradigm. Memory and Cognition, 25, 345-351.

Humphreys, M. S., Bain, J. D., \& Pike, R. (1989). Different ways to cue a coherent memory system: A theory for episodic, semantic, and procedural tasks. Psvchological Review. 96, 208-233.

Jacoby, L. L. (1991). A process dissociation framework: Separating automatic from intentional uses of memory. Journal of Memorv and Language. 30, 513-541.

Jacoby, L. L. (1996). Dissociating automatic and consciously controlled effects of study/test compatibility. Lournal of Memorv and Language, 35, 32-52.

Jasper, H. A. (1958). The ten-twenty system of the international federation. Electroencepholography and Clinical Neurophysiology, 10, 371-375.

Johnson, M. K., Hashtroudi, S., \& Lindsay, D. S. (1993). Source monitoring. Psychological Bulletin. 114, 3-28.

Johnson, M. K., Kounios, J., \& Nolde, S. F. (1996). Electrophysiological brain activity and memory source monitoring. NeuroRebort. 7, 2929-2932.

Johnson, M. K., Nolde, S. F., Mather, M., Kounios, J., Schacter, D. L., \& Curran, T. (1997). The similarity of brain activity associated with true and false recognition memory depends on test format. Psvchological Science. 8, 250-257.

Johnson, M. K., \& Raye, C. L. (1981). Reality monitoring. Psvchological Review. 88, 67-85.

Johnson, M. K., \& Raye, C. L. (1998). False memories and confabulation. Trends in Cognitive Sciences, 2, 137-145.

Johnston, W. A., Dark, V. J., \& Jacoby, L. L. ( 1985). Perceptual fluency and recognition judgements. Journal of Experimental Psychology: Learning. Memorv and Cognition. 11, 3-11.

Kensinger, E. A., \& Schacter, D. L. (1999). When true memories suppress false memories: Effects of ageing. Cognitive Neuropsychology, 16, 399-415.

Koutstaal, W., \& Schacter, D. L. (1997). Gist-based false recognition of pictures in older and younger adults. Journal of Memory and Lanquage, 37, 555-583.

Koutstaal, W., Schacter, D. L., Verfaellie, M., Brenner, C., \& Jackson, E. M. (1999). Perceptually based false recognition of novel objects in amnesia: Effects of category size and similarity to category prototypes. Cognitive Neuropsychology, $16,317-341$.

Kucera, H., \& Francis, W. N. (1967). Computational analysis of present-day American English. Providence, RI: Brown University Press.
Kutas, M., \& Hillyard, S. A. (1980). Reading senseless sentences: Brain potentials reflect semantic incongruity. Science. 207, 203-205.

Kutas, M., \& Van Petten, C. (1994). Psycholinguistics electrified: Event-related brain potential investigations. In M. Gernsbacher (Ed.), Handbook of psycholinguistics (pp. 83-143). New York: Academic Press.

Lehman, D., \& Skrandies, W. (1985). Spatial analysis of evoked potentials in man-A review. Progress in Neurobiologv. 23, 227-250.

Mather, M., Henkel, L. A., \& Johnson, M. K. (1997). Evaluating characteristics of false memories: Remember/know judgments and memory characteristics questionnaire compared. Memory and Cognition, 25, 826-837.

McClelland, J. L., McNaughton, B. L., \& O'Reilly, R. C. (1995). Why there are complimentary learning systems in the hippocampus and neocortex: Insights from the successes and failures of connectionist models of learning and memory. Psvchological Review. 102, 419-457.

McDermott, K. B., \& Roediger, H. L., III. (1998). Attempting to avoid illusory memories: Robust false recognition of associates persists under conditions of explicit warnings and immediate testing. Journal of Memorv and Language. 39, 508-520.

Melo, B., Winocur, G., \& Moscovitch, M. (1999). False recall and false recognition: An examination of the effects of selective and combined lesions to the medial temporal lobe/ diencephalon and frontal lobe structures. Cognitive Neuropsychology, 16, 343-359.

Murdock, B. B. (1982). A theory of the storage and retrieval of item and associative information. Psychological Review. 89, 609-626.

Norman, K. A., \& Schacter, D. L. (1997). False recognition in younger and older adults: Exploring the characteristics of illusory memories. Memory and Cognition, 25, 838-848.

Nunez, P. L. (1981). Electrical fields of the brain. New York: Oxford University Press.

O'Reilly, R. C., Norman, K., \& McClelland, J. L. (1998). A hippocampal model of recognition memory. In M. I. Jordan, M. J. Kearns, \& A. S. Solla (Eds.), Neural information processing systems (vol. 10, pp. 73-79). Cambridge: MIT Press.

Paller, K. A., \& Kutas, M. (1992). Brain potentials during memory retrieval provide neurophysiological support of the distinction between conscious recollection and priming. Journal of Cognitive Neuroscience, 4, 375-391.

Paller, K. A., Kutas, M., \& McIsaac, H. K. (1995). Monitoring conscious recollection via the electrical activity of the brain. Psychological Science, 6, 107-111.

Parkin, A. J., Bindschaedler, C., Harsent, L., \& Metzler, C. (1996). Verification impairment in the generation of memory deficit following ruptured aneurysm of the anterior communicating artery. Brain and Cognition. 32, 14-27.

Parkin, A. J., Ward, J., Bindschaedler, C., Squires, E. J., \& Powell, G. (1999). False recognition following frontal lobe damage: the role of encoding factors. Cognitive Neuropsychology, 16, 243-265.

Picton, T. W., Lins, O. G., \& Scherg, M. (1995). The recording and analysis of event-related potentials. In F. Boller \& J. Grafman (Eds.), Handbook of neuropsychology (vol. 10, pp. 3-73). Amsterdam: Elsevier.

Rapcsak, S. Z., Reminger, S. L., Glisky, E. L., Kaszniak, A. W., \& Comer, J. F. (1999). Neuropsychological mechanisms of false facial recognition following frontal lobe damage. Cognitive Neuropsychology, 16, 267-292.

Roediger, H. L. I. (1996). Memory illusions. Journal of Memory and Language, 35, 76-100.

Roediger, H. L. I., \& McDermott, K. B. (1995). Creating false memories: Remembering words not presented in lists. 
Journal of Experimental Psychology: Learning, Memory, and Cognition, 21, 803-814

Rubin, S. R., Van Petten, C., Glisky, E. L., \& Newberg, W. M. (1999). Memory conjunction errors in younger and older adults: Event-related potential and neuropsychological data. Cognitive Neuropsychology, 16, 459-488.

Rugg, M. D. (1995). ERP studies of memory. In M. D. Rugg \& M. G. H. Coles (Eds.), Electrophysiology of mind (pp. 1321170). New York: Oxford University Press.

Rugg, M. D., Fletcher, P. L. C., Chua, P. M.-L., \& Dolan, R. J. (1999). The role of the prefrontal cortex in recognition memory and memory for source: An fMRI study. Neuroimage, 10, 520-529.

Rugg, M. D., Mark, R. E., Walla, P., Schloerscheidt, A. M., Birch, C. S., \& Allan, K. (1998). Dissociation of the neural correlates of implicit and explicit memory. Nature, 392, 595-598.

Rugg, M. D., \& Nieto-Vegas, M. (1999). Modality-specific effects of immediate word repetition: Electrophysiological evidence. NeuroReport, 10, 2661-2664.

Rugg, M. D., Schloerscheidt, A. M., Doyle, M. C., Cox, C. J. C., \& Patching, G. R. (1996). Event-related potentials and the recollection of associative information. Cognitive Brain Research, 4, 297-304.

Rugg, M. D., Schloerscheidt, A. M., \& Mark, R. E. (1998). An electrophysiological comparison of two indices of recollection. Journal of Memory and Language, 39, 47-69.

Rugg, M. D., Walla, P., Schloerscheidt, A. M., Fletcher, P. C., Frith, C. D., \& Dolan, R. J. (1998). Neural correlates of depth of processing effects on recollection: evidence from brain potentials and positron emission tomography. Experimental Brain Research, 123, 18-23.

Schacter, D. L., Buckner, R. L., \& Koutstaal, W. (1998). Memory, consciousness, and neuroimaging. Philosophical Transactions of the Royal Society of London, Series B, 353, 1861-1878.

Schacter, D. L., Buckner, R. L., Koutstaal, W., Dale, A. M., \& Rosen, B. R. (1997). Late onset of anterior prefrontal activity during true and false recognition: An even-related fMRI study. Neuroimage, 6, 259-269.

Schacter, D. L., Curran, T., Galluccio, L., Milberg, W., \& Bates, J. (1996). False recognition and the right frontal lobe: A case study. Neuropsychologia. 34, 793-808.

Schacter, D. L., Israel, L., \& Racine, C. (1999). Suppressing false recognition in younger and older adults: The distinctiveness heuristic. Iournal of Memory and Language 40, 1-24.

Schacter, D. L., Norman, K. A., \& Koutstaal, W. (1998). The cognitive neuroscience of constructive memory. Annual Review of Psvchology 49, 289-318.

Schacter, D. L., Reiman, E., Curran, T., Yun, L. S., Bandy, D., McDermott, K., \& Roediger, H. L. I. (1996). Neuroanatomical correlates of veridical and illusory recognition memory: Evidence from positron emission tomography. Neuron. 17, 267-274.

Schacter, D. L., Verfaellie, M., \& Anes, M. D. (1997). Illusory memories in amnesic patients: Conceptual and perceptual false recognition. Neuropsychology. 11, 331-342.

Schacter, D. L., Verfaellie, M., Anes, M. D., \& Racine, C. (1998). When true recognition suppresses false recogni- tion: Evidence from amnesic patients. Journal of Cognitive Neuroscience, 10, 668-679.

Schacter, D. L., Verfaellie, M., \& Pradere, D. (1996). The neuropsychology of memory illusions: False recall and recognition in amnesic patients. Journal of Memorv and Language. 35, 319-334.

Senkfor, A. J., \& Van Petten, C. (1998). Who said what? An event-related potential investigation of source and item memory. Iournal of Experimental Psychologv: Learning. Memorv and Cognition. 24, 1005-1025.

Shiffrin, R. M., \& Steyvers, M. (1997). A model of recognition memory: REM-Retrieving effectively from memory. Psychological Bulletin and Review, 4, 145-166.

Smith, M. E. (1993). Neurophysiological manifestations of recollective experience during recognition memory judgments. Journal of Cognitive Neuroscience. 5, 1-13.

Srinivasan, R., Nunez, P. L., Silberstein, R. B., Tucker, D. M., \& Cadusch, P. J. (1996). Spatial sampling and filtering of EEG with spline-Laplacians to estimate cortical potentials. Brain Topograpbv. 8, 355-366.

Tendolkar, I., Doyle, M. C., \& Rugg, M. D. (1997). An eventrelated potential study of retroactive interference in memory. NeuroReport. 8, 501-506.

Trott, C. T., Friedman, D., Ritter, W., Fabiani, M., \& Snodgrass, J. G. (1999). Episodic priming and memory for temporal source: Event-related potentials reveal age-related differences in prefrontal functioning. Psychology and Aging. 14, 390-413.

Tucker, D. M. (1993). Spatial sampling of head electrical fields: The geodesic sensor net. Electroencephalograpby and Clinical Neuropbvsiology 87, 154-163.

Tucker, D. M., Liotti, M., Potts, G. F., Russell, G. S., \& Posner, M. I. (1994). Spatiotemporal analysis of brain electrical fields. Human Brain Mapping. 1, 134-152.

Tulving, E. (1985). Memory and consciousness. Canadian Psychologist, 26, 1-12.

Tun, P. A., Wingfield, A., Rosen, M. J., \& Blanchard, L. (1998). Response latencies for false memories: Gist-based processes in normal aging. Psychology and Aging. 13, 230-241.

Wilding, E. L. (1999). Separating retrieval strategies from retrieval success: An event-related potential study of source memory. Neuropsychologia. 37, 441-454.

Wilding, E. L., Doyle, M. C., \& Rugg, M. D. (1995). Recognition memory with and without retrieval of context: An event-related potential study. Neuropsvchologia. 33, 743-767.

Wilding, E. L., \& Rugg, M. D. (1996). An event-related potential study of recognition memory with and without retrieval of source. Brain. 119, 889-905.

Wilding, E. L., \& Rugg, M. D. (1997a). Event-related potential and the recognition memory exclusion task. Neuropsychologia. 35, 119-128.

Wilding, E. L., \& Rugg, M. D. (1997b). An event-related potential study of recognition memory for words spoken aloud or heard. Neuropsvchologia. 35, 1185-1195.

Yonelinas, A. P. (1994). Receiver-operating characteristics in recognition memory: Evidence for a dual-process model. Journal of Experimental Psychology: Learning. Memory. and Cognition, 20, 1341-1354. 


\section{This article has been cited by:}

1. Anett Galow, Sascha Tamm. 2008. Erlebnisbasierte und verfälschte Erinnerungen im EEG: Eine Pilotstudie. Forensische Psychiatrie, Psychologie, Kriminologie 2:1, 57-64. [CrossRef]

2. Angela Boldini, Salvador Algarabel, Antonio Ibañez, M. Teresa Bajo. 2008. Perceptual and semantic familiarity in recognition memory: an event-related potential study. NeuroReport 19:3, 305-308. [CrossRef]

3. Angela H. Gutchess, Yoko Ieuji, Kara D. Federmeier. 2007. Event-related Potentials Reveal Age Differences in the Encoding and Recognition of ScenesEvent-related Potentials Reveal Age Differences in the Encoding and Recognition of Scenes. Journal of Cognitive Neuroscience 19:7, 1089-1103. [Abstract] [PDF] [PDF Plus]

4. Jane E. Herron. 2007. Decomposition of the ERP late posterior negativity: Effects of retrieval and response fluency. Psychophysiology 44:2, 233-244. [CrossRef]

5. Grit Herzmann, Werner Sommer. 2007. Memory-related ERP components for experimentally learned faces and names: Characteristics and parallel-test reliabilities. Psychophysiology 44:2, 262-276. [CrossRef]

6. N. Azimian-Faridani, E. L. Wilding. 2006. The Influence of Criterion Shifts on Electrophysiological Correlates of Recognition MemoryThe Influence of Criterion Shifts on Electrophysiological Correlates of Recognition Memory. Journal of Cognitive Neuroscience 18:7, 1075-1086. [Abstract] [PDF] [PDF Plus]

7. Leslie J. Carver, Andrew N. Meltzoff, Geraldine Dawson. 2006. Event-related potential (ERP) indices of infants' recognition of familiar and unfamiliar objects in two and three dimensions. Developmental Science 9:1, 51-62. [CrossRef]

8. Andrew E. Budson, Daniel B. J. Droller, Chad S. Dodson , Daniel L. Schacter , Michael D. Rugg , Philip J. Holcomb , Kirk R. Daffner . 2005. Electrophysiological Dissociation of Picture Versus Word Encoding: The Distinctiveness Heuristic as a Retrieval OrientationElectrophysiological Dissociation of Picture Versus Word Encoding: The Distinctiveness Heuristic as a Retrieval Orientation. Journal of Cognitive Neuroscience 17:8, 1181-1193. [Abstract] [PDF] [PDF Plus]

9. J. E. Herron , E. L. Wilding . 2005. An Electrophysiological Investigation of Factors Facilitating Strategic RecollectionAn Electrophysiological Investigation of Factors Facilitating Strategic Recollection. Journal of Cognitive Neuroscience 17:5, 777-787. [Abstract] [PDF] [PDF Plus]

10. Christopher Summerfield, Jennifer A. Mangels. 2005. Functional coupling between frontal and parietal lobes during recognition memory. NeuroReport 16:2, 117-122. [CrossRef]

11. Thomas P. Urbach, Sabine S. Windmann, David G. Payne, Marta Kutas. 2005. Mismaking Memories. Psychological Science 16:1, 19-24. [CrossRef]

12. Doreen Nessler, David Friedman, Michael Bersick. 2004. Classic and false memory designs: An electrophysiological comparison. Psychophysiology 41:5, 679-687. [CrossRef]

13. Adam P. R. Smith, Raymond J. Dolan , Michael D. Rugg . 2004. Event-Related Potential Correlates of the Retrieval of Emotional and Nonemotional ContextEvent-Related Potential Correlates of the Retrieval of Emotional and Nonemotional Context. Journal of Cognitive Neuroscience 16:5, 760-775. [Abstract] [PDF] [PDF Plus]

14. Tim Curran, Joseph Dien. 2003. Differentiating amodal familiarity from modality-specific memory processes: An ERP study. Psychophysiology 40:6, 979-988. [CrossRef]

15. Rachel E. Goldmann, Alison L. Sullivan, Daniel B. J. Droller, Michael D. Rugg, Tim Curran, Philip J. Holcomb, Daniel L. Schacter, Kirk R. Daffner, Andrew E. Budson. 2003. Late frontal brain potentials distinguish true and false recognition. NeuroReport 14:13, 1717-1720. [CrossRef]

16. Jane E. Herron, Michael D. Rugg. 2003. Retrieval Orientation and the Control of RecollectionRetrieval Orientation and the Control of Recollection. Journal of Cognitive Neuroscience 15:6, 843-854. [Abstract] [PDF] [PDF Plus]

17. Doreen Nessler, Axel Mecklinger. 2003. ERP correlates of true and false recognition after different retention delays: Stimulus- and response-related processes. Psychophysiology 40:1, 146-159. [CrossRef]

18. Russell M. Bauer, Elizabeth C. Leritz, Dawn BowersNeuropsychology . [CrossRef] 